\title{
Effect of formaldehyde treated concentrate, urea and soybean meal on compound growth rate of milk yield and correlation studies in lactating cows
}

N.S. CHORE, S.D. CHAVAN, R. R. SHELKE AND P. A. KAHATE

Author for Corresponding -

\section{R. R. SHELKE}

Department of Animal Husbandry and Dairy Science, College of Agriculture, Dr. Panjabrao Deshmukh Krishi Vidyapeeth, AKOLA (M.S.) INDIA

See end of the article for Coopted authors'

\begin{abstract}
Present investigation entitled "effect of formaldehyde treated concentrate, urea and soybean meal on compound growth rate of milk yield and correlation studies in lactating cows" was undertaken at Department of Animal Husbandry and Dairy Science, Dr. Panjabrao Deshmukh Krishi Vidyapeeth, Akola. Feeding of 1.5 per cent formaldehyde treated 70:30 sugras : SBM concentrate mixture with 2 per cent added urea diet to lactating cows $\left(\mathrm{T}_{3}\right)$ was evaluated in relation to sugras untreated ration $\left(\mathrm{T}_{1}\right)$. It was observed that intakes in cows were non-significantly influenced by the parameters except water intake as out of the five animals only 2 animals showed significant impact due to DMI and TDNI and none of the animals due to DCPI. The values were $0.30,0.74,0.30$ and 0.28 per cent per week for DMI, DCPI, TDNI and TWI, respectively. This reflected in an increase of 1.14 per cent in milk yield/ week in cows. It was noticed that DCPI had a greater influence on milk yield of cows in all the groups except $T_{5}$ group as the correlation values were positive and significant, being $\mathrm{r}=$ $0.770,0.764$ and 0.921 of high magnitude in $\mathrm{T}_{1}, \mathrm{~T}_{2}$ and $\mathrm{T}_{3}$ groups, respectively and 0.588 of medium order in $\mathrm{T}_{4}$ group while it was positive but non-significant $(\mathrm{r}=0.431)$ in $\mathrm{T}_{5}$ group. The correlation values observed for maximum and minimum ambient temperature were positive non-significant, being $\mathrm{r}=0.186$ and $0.137,0.243$ and $0.074,0.324$ and $0.081,0.230$ and 0.067 and 0.250 and 0.094 in $\mathrm{T}_{1}, \mathrm{~T}_{2}, \mathrm{~T}_{3}, \mathrm{~T}_{4}$ and $\mathrm{T}_{5}$ treatments, respectively. In contrast correlation coefficient values between RHI and daily milk yield were negative non-significant in $\mathrm{T}_{1}, \mathrm{~T}_{2}$ and $\mathrm{T}_{4}$ treatments, being $\mathrm{r}=-0.481,-0.546$ and -0.424 , respectively while the association was negative significant in $\mathrm{T}_{3}(\mathrm{r}=-0.642)$ and in $\mathrm{T}_{5}(\mathrm{r}=-0.778)$.
\end{abstract}

KEY WORDS....... Formaldehyde, Sugras, Urea, Soybean meal, DMI, DCP, Milk yield, Compound growth rate, Correlation studies

HOW TO CITE THIS ARTICLE - Chore, N. S., Chavan, S. D., Shelke, R. R. and Kahate, P. A. (2017). Effect of formaldehyde treated concentrate, urea and soybean meal on compound growth rate of milk yield and correlation studies in lactating cows. Asian J. Animal Sci.,12(1): 61-69. DOI : 10.15740/HAS/ TAJAS/12.1/61-69.

ARTICLE CHRONICLE - Received : 19.04.2017; Revised : 12.05.2017; Accepted : 25.05.2017 